\title{
FRUTOS DE MI TIERRA: UN PUENTE ENTRE LAS NARRACIONES LITERARIA Y PERIOdí́STICA de MEdellí́N*
}

\author{
Frutos de mi tierra: A Bridge Between the \\ Literary and JoURNALISTIC NARRATIONS OF \\ MEDELLÍN
}

César Alzate Vargas ${ }^{1}$

Derivado de la investigación sobre las
dinámicas del periodismo literario en
Colombia, que el autor desarrolla para el
Doctorado en Literatura de la Universidad de
Antioquia.

Cómo citar este artículo: Alzate Vargas, C. (2019). Frutos de mi tierra: un puente entre las narraciones literaria y periodística de Medellín: tres propuestas estéticas. Estudios de Literatura Colombiana 44, pp. 47-62. DOI: https://doi.org/10.17533/udea.elc.n44a03

${ }^{1}$ cesar.alzate@udea.edu.co

Universidad de Antioquia, Colombia

Recibido: 15.08 .2018

Aprobado: 20.10.2018

Copyright: $@ 2019$ EstudiosdeLiteratura Colombiana. Este es un artículo de acceso abierto distribuido bajo los términos de la Licencia Creative Commons AtribuciónNo comercial - Compartir igual 4.0 Internacional 


\section{Un temprano ejemplo de periodismo literario}

Por los tiempos en que Tomás Carrasquilla era un recién llegado del municipio de Santo Domingo, en las por entonces lejanísimas montañas del nordeste de Antioquia, se produjo un hito inusual, y por mucho tiempo único, del periodismo colombiano: el relato del horrendo crimen de seis personas de una misma familia ocurrido en las afueras de Medellín. Los hechos sucedieron en la noche-madrugada del 2 al 3 de diciembre de 1873. El impacto que suscitaron en la sociedad local fue grande y se representó en los periódicos de la ciudad al ritmo en que, además, se resolvía el proceso judicial contra el grupo de asesinos, quienes fueron rápidamente identificados y aprehendidos.

Apenas casi cuatro meses después, el 30 de marzo del año siguiente, aparecía en la Imprenta del Estado de Antioquia, en formato de libro, El crimen de Aguacatal, el relato escrito por el periodista y funcionario judicial Francisco de Paula Muñoz. Tanto como el crimen, el texto de Muñoz conmocionó a la ciudadanía por el rigor de los datos y lo pormenorizado de una narración del todo atenida a la realidad y rica en recursos propios de la literatura. Fue un best seller a la medida de la época y de la ciudad, pero luego, por los azares de la memoria pública, se echó al olvido. El periodista y escritor Juan José Hoyos lo rescató de dicho olvido, gracias a los archivos de la colección de prensa de la Universidad de Antioquia, casi trece décadas más tarde. En 2002 publicó una edición del libro de Francisco de Paula Muñoz, enriquecida por un estudio sobre las circunstancias del crimen y del texto. En su estudio, Hoyos (2002) postulaba a El crimen de Aguacatal como un reportaje en todo el rigor del género, el primero que se hacía en Colombia (p. 99), lo que no deja de ser notable si se tiene en cuenta que investigadores de la historia del periodismo nacional tan autorizados como Daniel Samper Pizano no sitúan el surgimiento de este género en el país hasta la segunda década del siglo xx. Un fenómeno más extraordinario aun, el trabajo de Muñoz constituía de paso una tempranísima muestra de relato inscribible en el periodismo literario en formato de libro que apenas un siglo más tarde vería su eclosión en Colombia.

El crimen de Aguacatal es, en últimas, pionero en la narración del fenómeno urbano de Medellín desde los grandes géneros del periodismo; esto es, desde la no ficción. Incluso, sin desconocer algunos antecedentes - siempre menores - en ambas disciplinas, también es pionero en la narración de Medellín desde la literatura.

El siguiente hito lo produjo Tomás Carrasquilla. 


\section{Historia de una novela}

Todo empezó en una discusión de amigos: los que formaban parte del Casino Literario de Medellín hacia $1890 .{ }^{1}$ Años más, meses menos. La fecha exacta en que se produjo esta discusión es casi imposible de precisar, al decir de Jorge Alberto Naranjo (1996, p. 75) en uno de sus numerosos estudios en torno a la obra de Carrasquilla. La anécdota se confunde con la leyenda y toma distintos matices de acuerdo con el autor que se ocupe de ella, pero sí es claro que dicha discusión se centró en si existía o no materia novelable en Antioquia.

Tomás Carrasquilla fue invitado a formar parte del Casino en 1889 y para la ocasión debió escribir un cuento. Aparentemente sin su consentimiento, pero al fin y al cabo no para su disgusto, Carlos E. Restrepo incluyó dicha creación en un volumen dedicado a los miembros del grupo. Así relata el entonces sastre de Santo Domingo en su "Autobiografía la circunstancia de su ingreso al Casino y la publicación de "Simón el Mago"”.2

A nadie le contaba de mis escribanías. Ni siquiera a mi familia. Pero como la gente todo lo husmea y el diablo todo lo añasca, el día menos pensado recibí una nota por la cual se me nombraba miembro de un centro literario que dirigía en Medellín Carlos E. Restrepo en persona. Acepté la galantería, y como fuera obligación, sine qua non, producir algo para ese círculo, farfullé "Simón el Mago", para los socios solamente, según rezaba el reglamento. Pero Carlosé, que desde mozo la ha puesto muy cansona y por lo alto, determinó modificar la constitución y echar libro de todas nuestras literaturas. Aceptadísima fue por el publiquito antioqueño la miscelánea aquella. Allí salió mi relato, con seudónimo, por supuesto. ¡Y malón fue el que yo levanté, con todo y anagrama! Por eso descubrieron quién era el incógnito principiante (Carrasquilla, 1958a, p. XXv).

1 Cuenta Manuel Antolínez (seudónimo de Sebastián Mejía) que dicho grupo estaba formado por algunos jóvenes medellinenses que tras la guerra civil de 1885 "acometieron con ahínco los trabajos literarios". Ellos eran: Enrique W. Fernández, Carlos E. Restrepo, Eugenio Prieto, Juan de Dios Vásquez, Nicanor Restrepo, Rafael Giraldo y Viana, Carlos E. López, Camilo Villegas y G., Juan de la Cruz Escobar, Samuel Velilla, Joaquín E. Yepes, José de J. Villegas, J. P. Bernal, Sebastián Hoyos, Gonzalo Vidal, Enrique Ramírez G., Teodomiro Isaza, Antonio José Uribe y Javier Vidal. Como miembros honorarios, por residir fuera de la ciudad, participaban Francisco de Paula Rendón y Tomás Carrasquilla (Antolínez, 1896, p. 286). Este había tenido su primer contacto con los intelectuales jóvenes durante su residencia en Medellín una década antes, entre 1872 y 1877 . Distintos autores suman otros nombres al Casino, mismo que se convertiría luego en La Tertulia Literaria.

2 La "Autobiografía” de Tomás Carrasquilla apareció por primera vez en el número 237 del semanario ilustrado El Gráfico de Bogotá, correspondiente al 29 de mayo de 1915, y ha sido reproducida en múltiples oportunidades. La escritura de este texto esclarecedor tiene como origen una entrevista solicitada por la redacción del semanario a Carrasquilla y no concedida en principio por él. 
La fecha exacta del ingreso de Carrasquilla al Casino Literario es el 8 de agosto de 1889, según una cadena de precisiones que se inicia en 1928 en la edición número 12 de la revista Athenea de Bogotá y culmina en el poeta y novelista Darío Jaramillo Agudelo, en su prólogo a la edición facsimilar de Frutos de mi tierra, publicada por El Navegante Editores en conmemoración del primer centenario de la edición príncipe, en 1996. Entre tanto, el anagrama utilizado por Carrasquilla como seudónimo en la ocasión de su ingreso al Casino y la presentación de "Simón el Mago" fue Carlos Malaquita, y dada la proximidad del escritor a los asuntos de la minería no es de extrañar que el "Malaquita" hubiera sido pista fácil de seguir por cualquier allegado para reconocer su identidad. En cuanto a la famosa discusión, prosigue Carrasquilla (1958a):

Tratábase una noche en dicho centro si había o no había en Antioquia materia novelable. Todos opinaron que no, menos Carlosé y el suscrito. Con tanto calor sostuvimos el parecer, que todos se pasaron a nuestro partido; todos a una disputamos al propio presidente el llamado para el asunto. Pero Carlosé resolvió que no éra él sino yo. Yo le obedecí, porque hay gentes que nacen para mandar (pp. XXV-XXVI).

Y, en efecto, Carlos E. Restrepo había nacido para "mandar" más que para escribir. Cuando Carrasquilla redactó la famosa "Autobiografía", su amigo acababa de concluir el periodo presidencial de 1910 a 1914. El escritor fue desde su primera estancia en Medellín cercano a muchos personajes de la vida nacional; en la lista de sus allegados figura otro expresidente, Pedro Nel Ospina (1922-1926), quien escribiera el prólogo a la primera edición de Frutos de mi tierra en 1896.

El hecho es que Carrasquilla se dio a la labor de demostrar con obra su tesis de que no solo existía materia novelable en Antioquia, sino que además cualquier asunto relacionado con la condición humana, aun el más anodino y vulgar, era digno de interés para el escritor de novelas. Durante esos años, los últimos de su residencia en el pueblo natal y primeros de la década final del siglo XIX, se refirió a su trabajo en proceso como "el mamotreto". Muestras del mismo aparecieron en la Revista Santandereana de Bucaramanga en 1891 y en el diario El Espectador de Medellín en 1893. El mamotreto tuvo seis títulos: Jamones y solomos, Jamones y solomillos, Lonjas y tocinos, Jamones y tocinos, Tocinos y tasajos y, final y definitivamente, Frutos de mi tierra. Al parecer, el título definitivo le fue impuesto al autor por los primeros editores de la novela, Jorge Roa y Laureano García, y por lectores 
del manuscrito inicial como Rafael Pombo — podría haber sido este quien lo planteara-, y si bien al principio no fue de su agrado, asumió su defensa cuando amigos como Pedro Nel Ospina lo objetaron.

En una carta dirigida desde Bogotá el 14 de enero de 1896 a su abuelo Juan Bautista y a su tía Mercedes Naranjo, durante el proceso de edición de la novela, Carrasquilla señala con ironía que en la obra no solo hay unos "frutos muy podridos y hediondos, hay también otros de regular sabor, y algunos hasta gratos y perfumados" (1958b, p. 749). ${ }^{3}$ La principal objeción al título Frutos de mi tierra radicaba en la poca amabilidad de sus personajes como especímenes del animal humano natural de Medellín. Sus dos grupos de protagonistas, por un lado los hermanos Alzate y por otro lado la pareja de Martín Gala y la burlona Pepa Escandón, así como las gentes que los rodean, están tocados o por la avaricia y la falta de generosidad unos o por el apocamiento, la pose y el arribismo otros. Comerciantes y prestamistas despiadados, negociantes astutos, los dos Alzate mayores - Agustín y Filomena - , reducidas a sirvientas sin sueldo las menores - Belarmina y Nieves - ; estudiante inmigrado del Cauca y con pretensiones de gran señor Martín Gala, señorita de sociedad provinciana y con padre tiránico Pepa. A pesar de uno que otro momento de brillo individual, la narración no parece sentir especial afecto o entusiasmo por ninguno.

La novela - así se lo propuso el autor y bien ha demostrado su éxito la historia-, por su condición de naturalista y por su honda reflexión en torno al asunto, sobrepasaba al cuadro de costumbres y a su prima hermana la crónica, y venía a constituir el primer atisbo literario del ser de esta ciudad. Sentenciaría Carrasquilla (1958a) en la "Autobiografía" que su obra carecía de mérito y que de reconocérsele alguno sería el aparecer como "la primera novela prosaica que se ha escrito en Colombia, tomada directamente del natural, sin idealizar en nada la realidad de la vida" (p. XXvI). Y estas son dos razones por las que se le puede señalar como iniciadora del género de novela urbana no solo en la comarca antioqueña, sino en la nación literaria llamada Colombia, pero además se puede aventurar su interesante cercanía a los objetivos del relato periodístico, realista y naturalista por excelencia.

\section{La ciudad literaria}

Para hablar de la novela iniciática de Tomás Carrasquilla, se puede

3 El abuelo Naranjo era financista de la aventura literaria de Carrasquilla y de su traslado a Bogotá para el proceso de edición y publicación de Frutos de mi tierra. Juan Bautista Naranjo fallecería pocos meses después de la publicación de la novela. 
trazar una línea continua que se iniciaría en el naturalismo, pasaría por el costumbrismo y, constituyendo Frutos el primer hito de ella, terminaría en el divulgado fenómeno de la novela urbana de finales del siglo xx.

El naturalismo data de 1880, cuando Émile Zola publicó su ensayo $L a$ novela experimental. Una definición apenas suficiente habla del naturalismo como una teoría según la cual la composición literaria debe basarse en una representación objetiva y empírica del ser humano. Es de hecho bastante cercano al realismo y se dificulta el trazado de sus límites con este, si bien algunos intentan precisar que la diferencia entre ambos radica en que el naturalismo incorpora una actitud amoral en la representación objetiva de la vida. Estas características de ambas escuelas llevan necesariamente a la conclusión de que también constituyen unas de las fuentes nutricias en las cuales beberá el periodismo en general, y en especial el narrativo, que toma fuerza a partir de mediados del siglo xx.

Es posible que dicha actitud amoral sea la marca de la narración carrasquilleana, si bien alguien puesto en la tarea podría tal vez rebatirlo o al menos matizar su filiación y acercarlo más al realismo (y por consiguiente, desde luego, al posterior relato periodístico de corte narrativo). El mismo escritor se definía como naturalista y, pues la frontera entre las dos teorías es tan difusa, no es necesario esforzarse para contradecirlo; en todo caso la crítica y la academia han coincidido en comparar a Carrasquilla con escritores naturalistas como el mismo Zola, ${ }^{4}$ Benito Pérez Galdós, Leopoldo Alas "Clarín" y Vicente Blasco Ibáñez. En América Latina la irrupción de la novela realista es más o menos contemporánea al ensayo de Zola, y es aquí donde el escritor antioqueño encuentra cabida, ya que se enmarca al naturalismo en una corriente literaria en que los autores buscan, más que nada, analizar los problemas étnicos y sociales a través de la conducta de los personajes. Aquí es donde los Alzate, los Palma — sus vecinos pobres y despreciados-, los Escandón, los Gala se convierten en algo así como objetos de observación que sirven para descifrar la ciudad de la época. No en vano, Carlos E. Restrepo (1896), al saludar en un artículo publicado en la revista La Miscelánea dos meses después de la salida del libro, la publicación

$4 \quad$ Jorge Alberto Naranjo (1996) objeta esta comparación, diciendo que el naturalismo de Carrasquilla es "de buena pasta, entendámoslo, nada que ver con Zola" y enfatizando en que Frutos es una "novela de caracteres mejor que de costumbres" (p. 80).

En la carta ya reseñada del 14 de enero de 1896, el propio Carrasquilla señala con gracia la comparación que de su obra en proceso hace con la de Clarín el ensayista Laureano García (Carrasquilla, 1958b, p. 749). 
de Frutos de mi tierra, comentaba:

En efecto, los historiadores futuros, teniendo en cuenta que la novela de Carrasquilla es verídico traslado de algunas costumbres nuestras, encontrarán allí más datos para conocer nuestra sociedad, con sus defectos y cualidades, nuestro grado de cultura, \&c. [etc.], que en los periódicos y demás documentos de la época (p. 283).

A pesar de que se declara a sí mismo ajeno a cualquier escuela o sistema literario, Restrepo asimila la novela de su amigo al cuadro de costumbres en que numerosos críticos contemporáneos y posteriores la encasillarán más para su perjuicio que para el escudriñamiento de sus virtudes, si bien aclara que en su concepto el tal cuadro de costumbres es apenas una de las características de Frutos. Bien se sabe lo dañina que ha sido para la recepción de Carrasquilla su vinculación al costumbrismo, siempre tan insuficiente. Es decir: Carrasquilla en efecto acude en numerosos apartes de su primera novela - lo ha hecho en sus cuentos anteriores y lo seguirá haciendo en el resto de su obra - al cuadro de costumbres, pero ni se queda en él ni el costumbrismo como corriente literaria alcanza para definirlo. Se habla aquí del costumbrismo en su expresión más simple, ese que definen escritores como el cubano del siglo XIX José Victoriano Betancourt (citado por Bueno, 1983):

Las costumbres forman la fisonomía moral de los pueblos [...]. Muy humilde es mi pretensión: pintar, aunque con tosco pincel y apagados colores, algunas costumbres, bien rústicas, bien urbanas, a veces con el deseo de indicar una reforma, a veces con el de amenizar juntamente una página (p. XIX).

Para Jorge Alberto Naranjo (1996), Carrasquilla es una especie de sicólogo de la vida cotidiana y un pintor de caracteres. Un artista que toma la vida del natural y, sin narrar ningún suceso extraordinario ni a través de héroe alguno, es capaz de dar cuenta de un tipo humano universal (pp. 81-82). Apoya la idea que de sí mismo tiene el escritor al calificarse de naturalista. Y cuenta que ya el crítico Julián Páez (1896) se había percatado de esto cuando en su artículo de La Miscelánea decía:

¿Cuál, pues, el secreto de ese interés creciente? Ese secreto está en el cerebro del novelista: ese cerebro es creador, crea situaciones, las analiza, las dirige, las hace converger á un resultado; y allí donde el común de las gentes nada ve notable ni nuevo, ese cerebro sí ve, y calcula, y adivina, y extrae, como de oculto venero, las riquezas que para otros quedaron á la sombra. Y salen á relucir entonces pasiones que estaban escondidas, y acciones, al parecer insignificantes, pero que produjeron tales y cuales efectos extraordinarios, y sentimientos en que nadie se fijó, odios en embrión, ambicioncillas, amores en su cuna, vanidades que se ocultan modestamente, todo ese juego de simpatías y antipatías que es como el hilo de la existencia de las sociedades, todo eso se hace destacar del revuelto fondo por el cerebro pensador, que tiene tarea de buzo, y el público lector asiste, sorprendido, á 
esa exhibición de novedades, á esa singular clase de anatomía en grande escala... (pp. 259-260).

Allí donde a los otros el cuadro les sirve para mostrar las costumbres, al maestro antioqueño le sirve para desnudar en primer lugar el alma de un pueblo, y en segundo lugar y sobre todo, el carácter de lo humano. Que este carácter esté puesto en un punto específico de la geografía y en un momento específico del tiempo, es simple circunstancia: los Alzate, los Escandón, los Gala se hallan en Medellín, Antioquia, Colombia, a finales del siglo XIX, como podrían hallarse en cualesquiera otras coordenadas espacio-temporales. El propio Carrasquilla (1958b) lo especifica en la "Homilía $\mathrm{N}^{\circ}$ 1":

No os intime la región: el punto geográfico y el medio, nada importan. Bajo accidentes regionales, provinciales, domésticos, puede encerrarse el universo; que toda nota humana que dé el artista, tendrá de ser épica y sintética, toda vez que el animal con espíritu es, de Adán acá, el mismo Adán con diferentes modificaciones (p. 672).

Y, sin embargo, resulta fundamental la pertenencia de Tomás Carrasquilla y su universo literario a esas coordenadas específicas. Ya se ha dicho y sostenido, y seguirá diciéndose y sosteniéndose en este artículo, que a él le correspondió el papel de iniciador. No fue el primero que mencionó a Medellín en el plano de lo escrito, pero sí fue el primero que logró trasladar a las palabras la esencia de la ciudad.

Realismo, naturalismo, costumbrismo, literatura urbana (y crónica y reportaje, mediados estos dos, por ser géneros literarios del lado del periodismo, por la imposibilidad de la ficción) son en síntesis términos de gran proximidad entre sí. Y todos en alguna medida describen la obra de Carrasquilla.

Para el escritor Guido Tamayo (2009), "la ciudad puede ser perfectamente un tema literario, escogido por el interés o la necesidad de un autor determinado". Apunta que escritores urbanos no son aquellos que se refieren a la ciudad a través de una simple nominación de calles, de bares en esas calles, de personajes en esos bares, "como si la descripción más o menos pormenorizada de esas pequeñas geografías nos develara una ciudad en toda su complejidad" (p. 7). Asimismo, señala que lo urbano no es necesariamente lo que ocurre en la urbe y aclara que una narración puede ubicarse en la ciudad, pero referirse a una forma de pensar, actuar y expresarse ajena al universo comprendido por lo urbano. Concluye: "En consecuencia se podría afirmar que la narrativa urbana es aquella que trata sobre los temas y los comportamientos que ha generado el desarrollo de lo urbano y siempre a través de unos lenguajes peculiares" (p. 8).

Y yendo específicamente a la ciudad de Carrasquilla en sus Frutos, el 
colombianista estadounidense Raymond L. Williams indica que el referente de la novela es un Medellín en transformación. En efecto, la que durante la Colonia y las décadas iniciales de la República había sido apenas una villa aletargada en un valle de la cordillera central de los Andes, y ni siquiera había tenido una participación activa en la colonización que a lo largo del siglo XIX llevara a cabo la "raza" antioqueña del occidente casi despoblado del país, despertaba ahora al ritmo paradójicamente dinamizador de las guerras civiles y las convulsiones políticas. "El auge del cultivo del café en Antioquia, a partir de 1880, fue causa importante para la transformación de aquel poblado en ciudad", ilustra (Williams, 1992, p. 169). La ciudad, pues, crecía, y atestiguaba la conformación de una nueva clase social capitaneada por empresarios y comerciantes (he ahí a los Alzate).

\section{El Medellín de Carrasquilla}

Dado que en el siglo XIX es imposible hablar de Colombia sin pensar en ella como en una suma de regiones-nación, aisladas unas de otras por las voluptuosidades de la geografía y en ocasiones enfrentadas en conflictos bélicos en los que el enemigo llegaba incluso a ser el Estado central, conviene visitar los conceptos de la académica estadounidense Doris Sommer. Al reflexionar sobre la idea de novela nacional, dice Sommer que en Latinoamérica se puede identificar como tal al libro frecuentemente requerido en la escuela secundaria como fuente de historia local y orgullo literario. En esta medida, en Colombia lo más cercano al concepto es María (1867) de Jorge Isaacs, aunque en algunos momentos hubo quien proclamara a La vorágine (1924) de José Eustasio Rivera. Es claro, sin embargo, que estas novelas no satisfacen a plenitud los requerimientos necesarios para una identidad colombiana de conjunto. Bastante han discutido escritores y estudiosos el tema. Y no faltan quienes ahora proponen como novela nacional una obra mucho más reciente, pero de un alcance más universal: Cien años de soledad (1967) de Gabriel García Márquez.

Raymond L. Williams cuenta que en los años veinte, cuando se agitó el asunto, Carrasquilla llegó a proponer la idea de una novela nacional basada no en la imagen de una persona, sino en valores nacionales. Y citando a Rafael Gutiérrez Girardot, Williams comenta (1992) que "las actitudes regionalistas de Carrasquilla podrían interpretarse también como un rechazo al poder central que ejercían los humanistas de la Atenas Suramericana", y recuerda que adicionalmente el antioqueño había proclamado en 1906, en su célebre "Homilía $\mathrm{N}^{\circ}$ 2", una forma de independencia literaria basada en 
la novela moderna pero liberada de modelos extranjeros (pp. 62-63). Entre tanto, en su historia crítica de la literatura colombiana, Rafael Gutiérrez Girardot hace un elogio de la obra de Tomás Carrasquilla en general y dedica la mayor parte de su comentario a la primera novela del antioqueño; destaca el hecho de que el autor de Frutos se alzara con una voz diferente en el contexto de una noción de cultura, la bogotana y por tanto la colombiana, encerrada en los conceptos menos renovadores y más sumidos en la anomia (Gutiérrez Girardot, 1982, pp. 467-471).

Así, se vuelve preciso mirar a novelísticas regionales que, en los límites de las dichas regiones, den cuenta de una identidad — nacional-. Aquí, el papel de un Carrasquilla, que se torna imprescindible para hablar, si no de Colombia, de la nación antioqueña. O de Colombia desde la nación antioqueña. ${ }^{6}$ Incluso más el Carrasquilla de La Marquesa de Yolombó (1928) que el de Frutos de mi tierra, sin desconocer de ninguna manera el carácter fundacional de esta no solo por haber sido escrita y publicada mucho antes, sino por su papel de primera respuesta a la inquietud por la materia novelable de la región. El académico Ramón de Zubiría (1984) mencionaba en su prólogo a la edición de La Marquesa, en la colección Joyas de la Literatura Colombiana, la gracia en la actitud humana y en el manejo de la lengua, que el escritor conocía profundamente, y en la proyección vernácula de su provincia, proyección que al prologuista le recordaba a Cervantes (p. IV). Sobre esta novela, dice Williams (1992) que "es una síntesis del proyecto de su autor sobre la novela nacional, basada en valores regionales" (p. 63).

Retornando a Doris Sommer (2004), señala ella:

Hacia el final del siglo XIX, cuando la prosperidad económica y las políticas "científicas" del Estado produjeron una división intelectual del trabajo, el péndulo literario alejó a los escritores de los asuntos relacionados con el Estado. Esto los eximió de responsabilidades políticas y les permitió desarrollar el preciosismo del modernismo, sobre todo en la poesía, o exilió a los narradores hacia las fronteras pesimistas del "naturalismo" (p. 21).

El concepto se aplica perfectamente a Carrasquilla. Por su parte, De Zubiría (1984) recalca el agudo poder de percepción que le permite al narrador [...] sorprender las más sutiles variantes en el comportamiento social y sicológico; sensibilidad para la captación y comprensión de los altibajos de la conducta humana

6 Por supuesto, resulta problemático el uso del término nación antioqueña. Estrictamente hablando, si a duras penas puede hablarse de una nación colombiana, más difícil aun es hablar de naciones conformadas en el territorio colombiano por algunas de sus regiones. A pesar de que para determinados estudiosos la región paisa es de hecho lo más parecido a una nación que se ha dado en Colombia, aquí se utiliza el término solo para mencionar el territorio geográfico y humano, cultural, desde el que habla Tomás Carrasquilla. 
[...] y esa extraña virtud de poder elevar lo anecdótico y particular a las esferas de lo trascendente y universal (p. IV).

Como puede inferirse, esas virtudes del Carrasquilla de La Marquesa ya estaban bien presentes, treinta años antes, en el de Frutos, y en este lo más interesante es el asunto de la ciudad, de lo urbano (¿como escenario de lo humano?). El autor y su narrador conocen de sobra la naturaleza de la región-nación — para no abandonar a Sommer - y de la ciudad-escenario de lo humano. En lo referente a la primera, el espíritu antioqueño finisecular queda patentemente descrito cuando al final de la historia les llega a los Alzate la noticia de que en Bogotá ha muerto su hermana Filomena, y Agustín, deformada versión del patriarca de antaño, reacciona primero insultando a la sirvienta que le da la noticia y luego derrumbándose en el estupor que le produce el mal destino de su hermana preferida:

-¡Ah, maldita!... ¡Ojalá se hubiera...! ¡No, no: pobrecita!... ¡No, no! ¡Imposible que se hubiera muerto!... ¡Una mujer tan rica..., que tenía tanta capacidá pal negocio...! ¡Ese infame la mató!... ¡La envenenó!... ¡La plata no sirve sino pa uno condenase!... ¡No sirve pa más!... (Carrasquilla, 1997, p. 366).

Esto es lo que tanto incomoda de la novela a muchos antioqueños de la época, que se niegan a reconocer en ella los "frutos de su tierra": que tal sea el prototipo humano plasmado al natural en la primera novela representativa de la región. Que tales sean los valores de la nueva burguesía dominante. Tomás Carrasquilla supo dar cuenta del proceso histórico que se vivía en el país paisa, del rápido avance de su ciudad capital, que de villa adormecida pasaba a ser ciudad de comerciantes, para ser luego ciudad industrial y crecer al ritmo del siglo xx. En cuanto a la villa, así la describe en el primer segmento del abigarrado capítulo X, "La mar de cosas":

[...] a Medellín, la hermosa, le acontece lo propio: todo el año muy formal y recogida en sus quehaceres, trabajando como una negra, guardando como una vieja avara, riendo poco, conversando sobre si el vecino se casa o se descasa, sobre si el otro difunto dejó o no dejó, rezando mucho, eso sí... (1997, p. 131).

Posteriormente la deja ver por los ojos del despreciable César Pinto, el bogotano (habría que hablar de la Bogotá de Carrasquilla) que viene a aprovechar las mezquindades de la familia (es él a quien se refiere Agustín cuando señala a "ese infame"):

Medellín le parece el más concentrado emporio de gente sosa. ¡Hombres más pacatos, más patanes y erizos que los de Antioquia!... Las mujeres no las conoce sino de vista; pero, por encima, bien comprende que si acaso tienen alma es de vaca. Ha visto algunas bellas; pero con la belleza boba de los santos de papel. Sus conocidos desde Bogotá los ha hallado fríos, egoístas y antipáticos; ha desplegado con ellos toda su amabilidad... y como si arara en el mar (p. 266). 
Medellín era entonces una ciudad de unos treinta mil habitantes. Su desarrollo urbano tenía como referente máximo el río que recorre el valle y que a finales del siglo XIX estaba en proceso de ser dominado, mediante la canalización de su cauce primero y el secado de las tierras aledañas después, para en el xx derrotarlo y convertirlo en el vertedero de aguas negras que es en el XXI.

El tiempo de la escritura de Frutos de mi tierra coincide con el final del tiempo de la narración en la década de 1890. Así refieren el estado de la ciudad en dicha década Roberto Luis Jaramillo y Diego Suárez Vallejo (2004):

En Medellín querían muy pomposas las celebraciones de los 400 años de la llegada de Cristóbal Colón; y era obligatorio que el sabio anciano Manuel Uribe Ángel se manifestara, por cualquier vía. Meses antes le había publicado unas cartas el editor bogotano Isidro Laverde Amaya, en las cuales describía a Medellín con su entorno. Como médico le preocupaban los suelos bajos y anegadizos cercanos al río, cenagosos en tiempo invernal, que había que desecar para mantener la salud pública asegurada; en ese entonces ya no solamente se seguían haciendo cuelgas para rectificar el río sino que se hablaba de aumentar su velocidad con profundizar su cauce (p. 41).

Luego citan una de las aludidas cartas del médico Uribe Ángel. En la misma es de observarse la diferencia de tono con la narración de Carrasquilla:

Se dará pronto con el Puente de Colombia sobre el río Medellín; y es colocado sobre él y extendiendo la vista en todas las direcciones, como se pueden contemplar los más lindos paisajes de la comarca; porque las curvas del río, los bosquecillos de sauces, la brillantez del cielo, la suavidad del aire, los encantos del agua en movimiento, el azul de las cordilleras, la concurrencia de los vecinos y la vida en toda su plácida armonía, se nos ofrecen allí como en campo paradisíaco (Jaramillo y Suárez Vallejo, 2004, pp. 41-42).

Y, sin embargo, el desagrado de ciertos lectores por el tipo local descrito en la novela de Carrasquilla es muy inferior a la reacción que ella genera por sus virtudes literarias. El entusiasmo es inmediato y la recepción por parte de lectores, críticos y académicos es amplia y tiene resonancias nacionales. Acaba de salir el libro de la imprenta de Medardo Rivas en Bogotá y ya está apareciendo en La Miscelánea de Medellín, aunque firmado desde la capital por Julián Páez (1896), el primer ensayo laudatorio:

La descripción de Medellín y de El Cucaracho, para los que no conocemos aquellas tierras, son una provocación que á esas comarcas nos atraerá de por vida. No he tenido la fortuna de ir á Antioquia, y no puedo decir, por tanto, si los tipos descritos por el novelista son, ó no, los que privan generalmente en las diversas clases sociales que él pinta; pero sí puedo afirmar que, con las diferencias impuestas por la naturaleza, el mondus vivendi, la educación y otras causas, esos tipos se hallan también en otros puntos del país, en análogas clases sociales. ¡Que el novelista ha 
exagerado! dirán algunos. Sí, señores: el Sr. D. Pedro Nel responde á esto en el prólogo, con la cita que hace de Macaulay: los mejores retratos tienen siempre algo de caricatura (p. 261).

Numerosos ensayos siguen al de Páez. El Montañés de Medellín —la revista en que el propio Carrasquilla publica cuentos y artículos — también es entusiasta en la recepción de la primera novela antioqueña: “¡Siempre hube deseado hallar en las producciones literarias de Colombia la combinación artística de los elementos indígenas; que dejara el extranjero de imprimir su sello en nuestra obra original, como si estuviéramos condenados a la limitación eterna!” (Montoya, 1897, p. 105).

\section{Medellín de los escritores}

Según el profesor Augusto Escobar Mesa (1995), en su prólogo a la edición que publicaran la Universidad de Antioquia y el Municipio de Medellín de la novela Una mujer de 4 en conducta de Jaime Sanín Echeverri, para Manuel Mejía Vallejo no es hasta la aparición de dicha novela, en 1946, que se hace un intento serio de novelar a Medellín (p. XI). Curioso pensamiento en un escritor al que — no siempre para su fortuna — se señaló como heredero de Tomás Carrasquilla en la segunda mitad del siglo xx. Lo cierto es que cincuenta años antes de Sanín Echeverri y ochenta antes del boom de la literatura sobre Medellín, ya Frutos de mi tierra era un intento a la vez serio y exitoso de novelar la ciudad, con un ingrediente adicional interesante: al decir de Raymond L. Williams (1992), asistimos en esta novela al paso de una cultura oral en la Antioquia del siglo XIX a la escrita de Medellín a principios del xx (p. 169).

Nadie ha hablado del mencionado boom como un movimiento o una coincidencia de autores y obras pensando a Medellín desde los años setenta del último siglo, pero sí que puede plantearse su existencia. El mismo Mejía Vallejo podría señalarse como iniciador del mismo, cuando en 1973 gana el premio Vivencias y publica Aire de tango, una novela de la entraña de la ciudad, parecida a la de Carrasquilla en su forma de aproximarse a un Medellín que ya era tan distinto del de Frutos: esta aproximación se produce desde el lenguaje popular, del que el narrador se apropia para contar su historia. Al decir de Helena Araújo (1980) en su estudio sobre la novela colombiana de la década del setenta, "Logrando que el lenguaje sea parte integral de la realidad penetrada" (p. 162). La misma década ve la publicación de una novela que mira a Medellín desde la orilla opuesta; esto es, desde la burguesía: Hojas en el patio (1977) de Darío Ruiz Gómez. 
El ya referido profesor y también escritor y narrador de la ciudad Jorge Alberto Naranjo (1986), quien participó con otra decena de estudiosos en el encuentro La ciudad en la literatura, decía en su ponencia:

Al querer dar al objeto de nuestro asombro la forma plástica que se merece, todos hemos descubierto que no poseíamos las palabras para hacerlo. Hay algo terriblemente abstracto en Medellín, una forma persistente que se rehúsa a la descripción, que se muestra sin embargo cotidianamente y nos desafía (p. 93).

\section{Medellín de los periodistas}

Una pesquisa a la numerosa prensa local permite atisbar que el siglo XIX fue amplio en textos que, desde la no ficción, hacían el intento de narrar la ciudad con recursos propios de la literatura. En este sentido, géneros como la crónica y el cronicón se emparentaron con las corrientes literarias de la época, en especial las mismas que influyeron en Tomás Carrasquilla. No obstante, los textos de gran formato demorarán en aparecer todavía un siglo. Son las décadas finales del xx y los comienzos del Xxi los que ven el fulgor de una pléyade de periodistas que logran conquistar la literatura en los grandes géneros de la crónica y el reportaje.

Es claro que el gran periodismo solo se aparta de la literatura en un elemento ya mencionado antes aquí: la ficción. Muchos periodistas colombianos experimentaron en la primera mitad del xx con los recursos de la literatura para escribir sus historias, pero cometieron el pecado mortal de dejarse tentar por la ficción. A guisa de ejemplo, para citar uno de los rescates que la posteridad hizo posible gracias a la hemeroteca de la Universidad de Antioquia, es factible mencionar al bogotano José Joaquín Jiménez.

Puede parecer redundante, pero es necesario decir que la discusión de fin de siglo lleva a uno de los escasos consensos de la deontología periodística: la absoluta prohibición de usar elementos de ficción en los relatos. En este sentido, periodistas-escritores de gran valía literaria como Alonso Salazar y José Alejandro Castaño se han visto enfrentados a la incredulidad, sobre todo de la academia, al incluir el primero un personaje abiertamente ficticio en su libro La parábola de Pablo (2001) y al permitir el segundo que haya sospechas sobre la veracidad de sus datos en los libros que ha publicado. Es justo advertir, en todo caso, que al hablar de Salazar y su obra periodística se deben mencionar dos títulos fundantes del periodismo narrativo en formato de libro sobre la ciudad, ambos libres de la sospecha de incluir elementos ficticios: No nacimos pa' semilla (1990) y Mujeres de fuego (1993).

Otros tres nombres y sus relatos extensos en formato de libro pueden 
considerarse ejemplos muy bien logrados de periodismo narrativo y de corte literario al servicio de eso que Juan José Hoyos (1986) identificaba en una conferencia como la "historia de un alma" para hablar de su concepto de buena literatura (p. 36). Hoyos defiende la idea de que no se precisan las escuelas, que no hay que hablar de literatura urbana en Tomás Carrasquilla ni en sus sucesores, sino de textos bien o mal logrados en función de lo dicho arriba.

El primero de esos nombres es el del periodista Carlos Mario Correa, quien recoge el testimonio de sus años como corresponsal del diario $E l$ Espectador, justo por la época en que dicho medio se erigía como la máxima autoridad moral del país en la lucha contra el narcotráfico: Las llaves del periódico (2008, coescrito con el académico Marco Antonio Mejía). Pocos años después, Jorge Mario Betancur rescata del olvido las historias de un grupo de mujeres sometidas por la 'atrabilis' de los Agustos posteriores al de Carrasquilla en la realidad de la urbe del siglo xx, en Déjame gritar (2013), mientras que Juan Guillermo Romero diseccionará en sus Vidas de feria (2013) el microcosmos de Medellín en su feria de ganados.

Desde luego sin ser los únicos, estos cuatro nombres y los títulos mencionados se identifican como remotos continuadores de eso que inició Tomás Carrasquilla con sus Frutos: el relato último de lo que Medellín es. Hablamos, pues, de una novela que por las características de su narración y por la disección que hace de sus personajes se acerca bastante al periodismo $\mathrm{y}$ de unos relatos periodísticos que por el vuelo de su estilo alcanzan los terrenos de la literatura.

\section{Referencias bibliográficas}

1. Antolínez, M. (1896, abril). Palique. La Miscelánea 8, pp. 285-293.

2. Araújo, H. (1980). La novela colombiana en la década del 70. Eco. Revista de la Cultura de Occidente 230, pp. 160-174.

3. Bueno, S. (1983). Costumbristas cubanos del siglo XIX. Madrid: Biblioteca Ayacucho.

4. Carrasquilla, T. (1958a). Autobiografía. En Obras completas. Tomo I (pp. XXV-XXVII). Medellín: Bedout.

5. Carrasquilla, T. (1958b). Obras completas. Tomo II. Medellín: Bedout.

6. Carrasquilla, T. (1997). Frutos de mi tierra. Bogotá: Norma.

7. De Zubiría, R. (1984). Prólogo. En T. Carrasquilla. La Marquesa de Yolombó (pp. I-v). Bogotá: Círculo de Lectores.

8. Escobar Mesa, A. (1995). Prólogo. En J. Sanín Echeverri. Una mujer de 4 en conducta 
o la quebrada de Santa Elena (p. XI). Medellín: Editorial Universidad de AntioquiaAlcaldía de Medellín.

9. Gutiérrez Girardot, R. (1982). La literatura colombiana en el siglo xx. En Manual de historia de Colombia. Vol. III (pp. 476-471). Bogotá: Colcultura.

10. Hoyos, J. J. (1986). El barrio, las esquinas, los muchachos, la ciudad y los problemas de la novela. En La ciudad en la literatura. Encuentro (pp. 29-45). Bogotá: Icfes.

11. Hoyos, J. J. (2002). Un pionero del reportaje. Francisco de Paula Muñoz y El crimen de Aguacatal. Medellín: Hombre Nuevo Editores.

12. Jaramillo, R. L. y Suárez Vallejo, D. (2004). La sede de Otrabanda. Medellín: Suramericana de Seguros.

13. Montoya, J. (1897, noviembre). Tomás Carrasquilla. El Montañés 3, pp. 105-112. Medellín.

14. Naranjo, J. A. (1986). La novela de Mario Arrubla: la infancia legendaria de Ramiro Cruz. En La ciudad en la literatura. Encuentro (pp. 93-96). Bogotá: Icfes.

15. Naranjo, J. A. (1996). La atrabilis de Agusto. En T. Carrasquilla. Frutos de mi tierra. Tomo II: Textos críticos (pp. 75-85). Medellín: Gobernación de Antioquia.

16. Páez, J. (1896, marzo). Frutos de mi tierra. En La Miscelánea 7, pp. 258-261. Medellín.

17. Restrepo, C. E. (1896, abril). Novela tenemos. La Miscelánea 8, pp. 281-285. Medellín.

18. Sommer, D. (2004). Ficciones fundacionales. Las novelas nacionales de América Latina. Bogotá: Fondo de Cultura Económica.

19. Tamayo, G. (2009). Prólogo. En Cuentos urbanos (pp. 7-9). Bogotá: Panamericana.

20. Williams, R. L. (1992). Novela y poder en Colombia. 1844-1987. Bogotá: Tercer Mundo Editores. 